\title{
Signs, Things and Packaging: Recovering the Material Agency of the Cigarette Packet
}

\author{
Kirsten Bell \\ University of Roehampton
}

\begin{abstract}
In recent years, cigarette packets have become the site of considerable legislative attention via initiatives to remove industry branding from tobacco products, based on the premise that branded cigarette packaging acts as a 'silent salesman' for smoking. According to this perspective, the cigarette packet has a particular sort of agency, but one rooted in its communicative powers rather than its material qualities. In this paper I reconsider this view, based on an analysis of archives in the Truth Tobacco Industry Documents Library produced by a search of the term 'packet design', and scholarship on containerization. Taking up the idea of containers as undertheorized forms of materiality, I argue that the cigarette packet is best conceptualized as a technology with powerful, albeit largely invisible, physical consequences on the circulation of cigarettes and the practice of smoking itself.
\end{abstract}

Keywords: packaging, cigarettes, smoking, materiality, technology, standardization, containerization

\section{Introduction}

I met Jeannie in the summer of 2014 in an eastside Vancouver neighborhood as part of a study I was conducting about how smokers engage with the warning labels on their cigarette packets. A white woman in her mid-60s, Jeannie was standing out the front of a Starbucks, cup of coffee in one hand and a cigarette in the other. With her carefully styled short hair and garbed in white sneakers, white blouse and colorful capris, Jeannie looked somewhat out of place in a neighborhood dominated by hipsters and homeless people, which is partly why I noticed her. I stopped and introduced myself, explaining the nature of the study, and Jeannie immediately launched into a tirade about the packaging, noting that she'd called a hotline to complain about it. Pleased by her interest, albeit a little taken back by her vehemence, I told her she was exactly the sort of person I was interested in speaking to, although I was somewhat confused about how she'd made a formal complaint. "How did she even get Health Canada's number?" I thought to myself, wondering whether she'd called the quitline listed on the warning label by mistake. 
I asked what Jeannie disliked about the packet, anticipating a dissection of the warning labels, and, sure enough, she pulled her packet of Players out of her bag to show me. But rather than focusing on the warning label, with its large and ominous picture of an empty cot and "Tobacco smoke hurts everyone" message, she slid it open for my inspection. Somewhat confused, and still waiting for the punchline, it took me a few moments to grasp the implications of her demonstration. It finally dawned on me that although we were both talking about cigarette 'packets', we weren't referring to the same thing. While I was interested in its attributes as a visual sign, Jeannie was focused on its qualities as a material object. The source of her irritation was thus not the images it bore but the opening mechanism, whereby the packet is slid sideways out of its case. As Jeannie explained, this 'innovation'1 meant that she never knew how many smokes her pack contained, unlike its flip-top counterpart.

During encounters such as these, I was repeatedly forced to consider the materiality of the packet, along with its relative invisibility in accounts of the power of cigarette packaging (see Bell et al., 2015). Despite the current legislative interest in cigarette packets - an interest that reaches its apotheosis in 'plain' or generic packaging legislation ${ }^{2}$ - packets are understood primarily as a mobile sign. This is strongly evident in the field of tobacco control, where research has focused almost exclusively on the visual aspects of packaging and their relationship with smoking. As Wakefield and colleagues observed seventeen years ago, "Of research papers on [cigarette] packaging published since 1990, most have focused upon health warnings and generic packaging" (2002: i73). More recent reviews of tobacco control research on cigarette packaging suggest that little has changed in the intervening years (e.g., Hammond, 2011; Moodie et al., 2012; Stead et al., 2013; Monárrez-Espino et al., 2014; Noar et al., 2016a, 2016b). For the most part, the material qualities of the packet are either ignored entirely, or, in the rare instances where 'structural innovations' are considered (e.g., Moodie et al., 2012), these are discussed purely as vectors of branding. ${ }^{3}$ This is in line with the approach to tobacco packaging taken by the Framework Convention on Tobacco Control, ${ }^{4}$ Article 13 of which treats the packet's physical and visual features exclusively as a means to "cultivate and promote brand identity" (WHO, 2003:2).

In this framing, the packet's primary function is as a "bonsai billboard" (Pottage, 2013: 519). Animated by advertising and branding, the cigarette becomes status, freedom, danger, coolness, and so on, ad infinitum, with the unbranded packet key to nullifying its power. In such accounts, the packet has agency, but of a very particular sort: namely, that of a "silent salesman" (Chantler, 2014: 4; Chapman and Freeman, 2014: 35). This is primarily because the packet's qualities as a sign have subsumed its material agency as a thing. In what follows, I demonstrate the limitations of perspectives that fail to account for the materiality of the packet. To use the vocabulary of Charles Sanders Peirce (1998), who developed a theory of signs that accounted for the relationship between materiality and meaning, cigarette packets have an indexical as well as symbolic relationship with cigarettes: one based on physical connection as well as cultural mediation. It is this physical connection between cigarettes and packets that I aim to explore in this paper. My goal is to show that although often treated as a "boring backstage 
element" ${ }^{\prime 5}$ whose purpose is exclusively to house the front-stage 'salesmen', the thingness of the packet plays a critical role in the cigarette-smoker assemblage.

While my reflections are broadly informed by scholarship on materiality, of central inspiration has been work that approaches objects through the lens of standardization, especially Marc Levinson's 2006 book The Box. Standardization provides a particular lens into "the force of things in human affairs" (Braun and Whatmore, 2010: xiii) as its starting point is the material context in which standards are transformed into actions and effects (Dunn, 2009) - although this has obvious implications for the relationship between persons and things. While this paper has been stimulated in part by research with smokers in Vancouver, Canada on their engagements with cigarette packets, my thinking on this topic was indelibly changed following an encounter with the Truth Tobacco Industry Documents Library in 2018: an online archive of 14 million industry documents housed at the University of California San Francisco. Through readings of hundreds of reports, patents, minutes, newsletters and letters produced by a search of the term 'packet design', 6 it became starkly apparent that while the packet's communicative powers have long been of interest to tobacco companies, its value as a material container has also been of critical importance. Thus, via the lens of the documents I found in the archives, I aim to bring the packet into the spotlight and open it up as an intriguing technology with powerful, albeit largely invisible, material consequences on the circulation of cigarettes and the practice of smoking itself. In doing so, I challenge the prevailing orthodoxy that the cigarette packet is primarily a vehicle for advertising and branding and that its agency lies exclusively in its communicative powers.

\section{Branding, advertising and cigarette packaging}

According to the classical interpretation, advertising and branding are understood to operate as "a form of intermediary that translates material products into symbolic social entities" (Cronin, 2004: 1). Although this dematerialized view of advertising and branding has been challenged in recent years (e.g., Cochoy, 2002; Cronin, 2004; Lury, 2004; Arvidsson, 2006), it continues to dominate perceptions of cigarette packaging. In this respect, tobacco is rather different from other commodities such as food, where the material effects of packaging have long been of scholarly interest in addition to its importance as a marketing vehicle (see Hawkins, 2013 for an overview). These contrasting orientations towards food and tobacco are clearly illustrated in Packaged Pleasures: How Technology and Marketing Revolutionized Desire (Cross and Proctor, 2014), where the authors' discussion of cigarette packaging focuses primarily on the cigarette itself as a package, with the packet discussed primarily in relation to its importance as a means of differentiating between otherwise homogenous products. ${ }^{7}$

That a book otherwise very attentive to the materiality of packaging treats the cigarette packet largely as a marketing tool demonstrates just how pervasive this view is. It also begs the question of why the cigarette packet is so often treated exclusively as a sign vehicle. An answer of sorts is to be found in Cross and Proctor's assertion that, "For cigarette makers, packaging and specifically package art has steadily grown in significance, as manufacturers have lost access to most of their traditional advertising venues" 
(2014: 86). There is little question that when the packet itself became the primary means through which advertising could be realized, the packet took on new significance for the tobacco industry (see Wakefield et al., 2002). Thus, the overriding focus on the visual attributes of the packet in the field of tobacco control may be partially an artifact of the tobacco industry's renewed interest in packaging as a brand vehicle. ${ }^{8}$ However, I suspect that it is also a legacy of ways in which smoking has become a key cultural signifier of the power of advertising itself. To quote one fairly typical characterization, "cigarettes are inseparably intertwined with advertising and are the most spectacular proof of its efficacy" (Harrald and Watkins, 2010: 2). Certainly, they have furnished what has become the most iconic illustration of the power of advertising and branding: Philip Morris's rebranding of Marlboro cigarettes.

As is now widely known, in a bid to transform Marlboros from a 'sissy' brand to a bold masculine one, Philip Morris executive George Weissman employed a slew of consultants, public opinion experts and marketers (Brandt, 2007). The distinctive red and white packaging was developed by the design firm Fran Gianninoto \& Associates, in collaboration with Egmont Arens and Louis Cheskin of the Color Research Institute of America. They came up with eight trial package designs, with Cheskin conducting eye-movement tests and surreptitiously photographing shoppers' movements and packet choices to gauge the packaging's appeal (Brown, 2008). Cheskin then ran tests with 805 smokers to determine the most attractive motifs and colors; 80 percent favored a crest design and a package with bold red accents, which Cheskin explained in terms of the crest's unconscious association with quality and prestige and the added visibility the red gave the packet (Brown, 2008). With the branding now in place, Weissman turned to Leo Burnett (of 'Jolly Green Giant' fame) to devise an appropriate advertising campaign - one which ultimately featured rugged cowboys doing a variety of manly things in 'Marlboro Country'. According to Allan Brandt (2007), this campaign presented the beginnings of a new era of lifestyle advertising where image largely superseded text. In his words, "In a major breakthrough, not just for cigarettes but for advertising generally, Burnett's Marlboro ads would dispense with copy almost entirely and instead convey message and meaning exclusively through image" (p. 263). The rest, of course, is history, with Marlboros rapidly becoming the most popular brand of cigarettes on the planet - a status they retain to this day.

But there's a less frequently recounted side to the Marlboro story and the brand's rise to global dominance. Beyond the changes in its branding and advertising, Marlboros were the site of several other technical innovations. First, they were the original cigarettes to contain ammoniated tobacco sheet in addition to traditional tobacco leaf (Stevenson and Proctor, 2008). This, Robert Proctor (2011) argues, produced both a rich or 'chocolatey' taste (something prominently referenced in the brand's slogan "Come to where the flavor is. Come to Marlboro Country"), along with a more powerful nicotine kick. In his words, "It is impossible to say how much the success of Marlboro is due to freebasing and how much to the sophisticated marketing of Marlboro Country and the Marlboro Man" (Proctor, 2011: 399). 
The story is more complicated, still, because Marlboros were the site of yet another innovation, this time in cigarette packaging: the introduction of the flip-top, or hinge-lid, case. Generally credited to Molins, a British packaging company (Brandt, 2007), its website goes so far as to imply that the flip-top packet was largely responsible for the brand's success, noting:

The 1950s saw the introduction of the hinge-lid pack, which was originally invented and patented by Walter's son, Desmond Molins, in 1937. The hinge-lid pack was a major step forward from the previous soft packs, which allowed cigarettes to be damaged, and was used by Philip Morris in 1954 to relaunch the Marlboro brand: it was instantly successful and Marlboro sales increased 50 fold (Mpac Group, 2019).

These claims complicate the idea that advertising and branding alone were responsible for Marlboro's success. Yet, while we readily acknowledge the materiality of the cigarette (albeit primarily as a 'nicotinedelivery agent', which is Proctor's view), we rarely consider the materiality of the packet itself. Part of the problem is that as a physical container, cigarette packets seem utterly prosaic and uninteresting - an assumption I intend to challenge in what follows.

\section{Cigarette manufacturing and the invisibility of the packet}

Until the interwar period, ${ }^{9}$ there was considerable variation in the form of cigarette packets as well as in their graphic design. While many companies produced 'hull and slide' packets, ${ }^{10}$ others opened at the top to fully display their contents - much in the manner of a chocolate box. Packets also varied in their intended 'biography' (cf. Kopytoff, 1986). At one end of the scale were highly decorative packets made of board or metal that were clearly designed to outlive the cigarettes they contained (Russell, 2012). At the other end of the scale were so-called 'soft' packets made of flimsy paper and board: utilitarian in form and function, they were intended to be discarded after the cigarettes were smoked. In more extreme instances, cigarettes were dispensed from counter display boxes into paper packets and were presumably either transferred to a personal cigarette case or smoked immediately on purchase (Russell, 2012).

The sheer physical diversity of these early packets reveals how standardized cigarette packaging has become today. Yet, overviews of the mechanization of cigarette manufacturing generally begin and end with James Bonsack's invention of the cigarette rolling machine in 1880. For example, Brandt (2007:31) argues that Bonsack's machine, "assured new economies of scale and speed of production as well as long production runs". However, while a single machine may have been able to churn out a hundred thousand cigarettes per day, tobacco consumption ultimately relies not just on how quickly cigarettes can be created, but how speedily they can be packaged and distributed. As Proctor (2011:41) notes, "feeding and packing machines of comparable speed must accompany the machines to avoid bottlenecks". Thus, a seamless connection is required between cigarette making machines and packaging machines - from machines that insert cigarettes into packs, to those that insert packs into cartons, and cartons into cases, and so on (Cross and Proctor, 2014: 75-76). 
Cigarettes also need to be packaged in such a way that they will survive the distribution process intact. Rarely acknowledged in accounts of the spread of smoking is that the "little white slaver" constitution; easily crushed, it is also affected by exposure to moisture. As such, its container plays a critical role in ensuring that the cigarette makes its way into the hands of smokers fully intact. Yet, as Proctor (2011) observes, such machines and their accompanying processes have received virtually no attention from historians, policy makers or tobacco control experts. This is a perfect illustration of the ways in which the sheer material obviousness of cigarette packaging has served to ensure its conceptual invisibility, except where it declares its presence via branding.

In this respect, the cigarette packet is much like the picture frame as theorized by the art historian Ernst Gombrich by way of Daniel Miller (2010). For Gombrich, when a frame is appropriate, "we simply don't see it, because it seamlessly conveys to us the mode by which we should encounter that which it frames" (Miller, 2010: 49). According to Miller, a more radical interpretation of this thesis is that art exists only insofar as the frame proclaims it as such; thus, it's the frame, rather than the artwork itself, that elicits the response we give it as 'art'. Of course, this line of interpretation would imply that the relationship between the picture and the frame is primarily visual, which is precisely the position I'm trying to move away from in considering the relationship between cigarettes and their packets. But to push the frame analogy in a slightly different direction, the frame also arguably has a material connection with its content: it physically contains the artwork - especially when the latter is mass produced. After all, art reproductions are typically standardized: they are produced in standard sizes to fit into standard frames (e.g., 8 " x 10", 16" x 20"). In a very real sense, then, the size of the frame dictates the size of the artwork. Or, more specifically, the size and shape of the frame, the size, gauge and texture of the paper on which it is printed, along with the qualities of the printer itself, all combine to produce the artwork. The 'art' itself - like the cigarette - is only one part of this larger assemblage.

\section{Cigarettes and packets as a material assemblage}

While the visual design of the cigarette packet has been of longstanding interest to the tobacco industry, numerous documents in the Truth Tobacco Industry Documents Library demonstrate an intense focus on cigarettes and their packaging as a material-semiotic assemblage. A notable illustration can be found in a report published by British American Tobacco ${ }^{12}$ in 1953 titled "Notes on packaging" in a periodical newsletter titled Information: A Periodical Summary of Ideas from All Quarters. ${ }^{13}$ According to the report:

[O]ur Packaging has five main objectives:--

FIRST: Handling convenience so that transporters, traders and consumers can easily move, store or carry a convenient quantity or unit.

SECOND: For protection, as against breakage or rain or contamination by dirt, flies, etc.

THIRD: For preservation of inherent qualities_-to prevent 'goodness' escaping. FOURTH: For 'eye' appeal—design, colour, all the printing and all the decoration. 
FIFTH: For identification of contents by means of brand name, manufacturer's mark, or the like (BAT, 1953: 3).

The potential of the packet to preserve its contents was an area of particular interest, especially given the tropical environs of much of BAT's cigarette production. For example, a report on "The water vapour permeability of wrapping materials" highlights the need to maintain a careful moisture balance in cigarette packets to ensure that their contents remained undamaged (BAT, 1948). It goes on to provide a detailed overview of the company's experiments on this front, from plastic coatings and transparent films to tests on the expected life of a cigarette packet (see figure 1) based on its ideal moisture content (BAT, 1948: 17-18). Likewise, later reports discuss the development of experimental devices such as a hydrotester water meter to measure the 'moisture in a moving web of paper or board' (BAT, 1952: 17).

TABLE L. - PACKAGE UFE

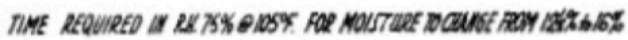

\begin{tabular}{|c|c|c|c|c|c|c|}
\hline & wimeng & arow & 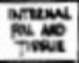 & 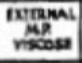 & sovous mevma & $\begin{array}{l}\text { moabt } \\
\text { Lift }\end{array}$ \\
\hline 1 & 1 & None & $N 0$ & 10 & 16 & the \\
\hline 2 & 10 & None & 16 & 16 & 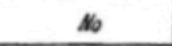 & 2 irs \\
\hline 3 & 10 & 10 & $M$ & 10 & No & $3 \mathrm{hras}$ \\
\hline 4 & $n$ & Nos & Yes & 10 & 16 & $36 / x$ \\
\hline 5 & $n$ & $N o$ & Yer & Yes & No & 10d\%s \\
\hline 6 & $b$ & share & 10 & tos & 16 & $7 d y s$ \\
\hline 7 & 500 & $10 s$ & 10 & $M$ & Mo & Iby \\
\hline 8 & 500 & br & 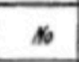 & 10 & $\begin{array}{l}\text { Ploin Kovft } \\
\text { (nish Kurp) }\end{array}$ & Iday \\
\hline 9 & 500 & los & Yes & 140 & 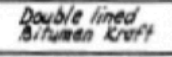 & $1 \mathrm{man} / \mathrm{h}$ \\
\hline 10 & 500 & os & Yess & Yes & $\begin{array}{l}\text { Doublo lined } \\
\text { Bithmen kent }\end{array}$ & 2 moelfy \\
\hline ॥ & 500 & Nos & Yer & $N_{0}$ & Kraft $\mathrm{Fal}$ & $8 \mathrm{mank}$ \\
\hline 12 & 500 & las & Yes & Yess & Kneft foll & Smantite \\
\hline 13 & 500 & $10 s$ & Wes & Yos & Foil/kraft/foil/ & Smentis \\
\hline
\end{tabular}

Figure 1. Life of a cigarette packet

Other tobacco companies were equally preoccupied with this issue. For example, a 1987 report from Philip Morris details the results of its Cigarette Design Project: a collection of three experimental products that aimed to improve the function and flavor of cigarettes. Although two of the products focused on cigarettes themselves, the third targeted the packet as a means of improving cigarette design. Titled "humidor pack", its objective was to "develop a system for maintaining the moisture content of packaged cigarettes” (Dwyer, 1987: 49). A potassium citrate/glucose solution was subsequently developed, which, when placed into cigarette packets, seemed to "give long-term cigarette-moisture stability" (p. 49). The report indicates that Philip Morris planned to further develop this system via its 
product innovation branch and a document from the following year advises that a manufacturer had been found to create the humidor packet (Callaham, 1988). Other reports from the period suggest that Philip Morris was also experimenting with packaging adhesives that might improve moisture retention in the pack (e.g., Philip Morris, 1988).

Such accounts reveal the ways in which the quality of the cigarette (namely, its taste and smell) was perceived to be inextricably bound up with the packet itself. However, recognizing these interrelationships requires us to think in a different way about containers, which we primarily tend to conceptualize in terms of absences rather than presences. This incapacity - and its deleterious consequences - are evident in Benjamin Whorf's (1941) description of the gasoline drum as an illustration of the ways in which language mediates perception. Based on his professional work as a chemical engineer for an insurance company, he observed that great care was typically exercised in the storage of full gasoline drums, but 'empty' drums tended to be treated carelessly, with people readily smoking around them, despite the fact that they contain highly explosive vapor. This, he argued, was because of the connotations of the term 'empty' as "null and void, negative, inert" (Whorf, 1941: 76). As Tim Ingold observes, we typically see materiality as residing exclusively in things, leading to an incapacity to consider what surrounds them - i.e., enclosures themselves. In his words, "Are we really to believe that whatever lies on the hither side of such objects is immaterial?" (2007: 6).

\section{Containerization and cigarette packets as a technology}

The insights offered by a focus on enclosures are clear in Marc Levinson's (2006) work on shipping containers. As Levinson convincingly demonstrates, this unassuming metal box became the core of a highly standardized and largely automated system for moving goods across the globe that had enormous impacts on countries, industries, manufacturing processes and workers. Of equal relevance are his insights into the ways in which goods were transformed by the need to make them containerizable and the role of the shipping container itself in shaping the objects it carried. Shipping containers thus exerted their effects both outwards and inwards, serving to transform ships, ports and cities on the one hand, and the goods they contained on the other. Arguably, these dual effects are also evident in cigarette packets, which had significant consequences on both cigarettes themselves and their global circulation.

This is strongly evident in British American Tobacco's post-war periodical Information: A Periodical Summary of Ideas from All Quarters, mentioned previously. As its name suggests, the newsletter was intended to present a forum for idea sharing amongst BAT's territorially dispersed operational teams, who operated exclusively outside of the British and American markets. ${ }^{14}$ These reports provide a fascinating record of the material conditions of cigarette production in the post-war period - from skin irritations in tobacco factories and infestations of tobacco beetles on plantations to issues with equipment maintenance and packaging materials. For example, issue \#14, focusing on India, describes a dearth in gum-sealing cellophane and the ingenious solution the local operations manager devised to resolve it: cheap domestic irons were transformed into a makeshift sealing machine for generic 
cellophane sheets (BAT, 1952). A more global problem, extensively detailed in issue \#15, was the shortage of wood pulp in the early 1950s. With international demand increasingly outstripping supply, dramatic fluctuations in the availability and price of paper and board were occurring, which caused no small amount of alarm amongst BAT executives (BAT, 1953). This theme continued in a later article in the same issue, which concludes: "The economics of Packaging are... illustrated by the total value of Packaging material in the possession of our Group: amalgamated figures show that the millions of pounds invested in Packaging materials and in Packaging machinery have climbed year by year" (BAT, 1953: 1).

The escalating costs of packaging remained an intense concern for BAT during the next two decades. This topic makes an appearance in meeting minutes throughout the 1960s and is the focus of a 1976 report on cigarette making and packing machines, which notes that "the capital required to make hinged lid packs is approximately $£ 400 /$ pack/minute, but 'real' costs have been rising at $4.1 \%$ per year and if that continues the $£ 400$ will have become $£ 730$ by 1990" (Kilburn, 1976: 6). In light of these concerns, it should come as little surprise to the reader that BAT began to invest in packaging companies. According to a 1964 Director's Report, the vast majority of BAT's non-tobacco investments were in the paper and printing/packaging industries (BAT, 1964). Moreover, a number of their engineering investments were also packaging related. For example, they invested in the Molins Machine Company - the company that developed the flip-top packet, and which produced a variety of cigarette making and packing machines. However, meeting minutes from this period indicate a rather tense relationship between the two companies, with Molins consistently behind schedule on delivering packing machines, to the consternation of both marketers (see BAT, 1962a) and company directors (see BAT, 1962b). Such accounts clearly demonstrate the reliance of tobacco manufacturers on cigarette packaging for the circulation of cigarettes, with shortages in packaging materials and machinery disrupting the entire production and distribution chain. I will have more to say on this below, but for the moment it's worth noting that the creation of smokers relied, in a quite literal sense, on the production of packets and the access to a steady stream of cigarettes they facilitated.

Further complicating matters was the synergistic relationship between cigarettes, packets and brands, with changes in any of these areas creating repercussions throughout the whole production process. Thus, innovations in cigarette making and packing machines were just as great a risk for tobacco companies as equipment breakdown and obsolescence - as were changes in branding themselves. To quote from the aforementioned 1976 report on cigarette machinery, "The trend towards increasing machine speeds would appear to make brand innovation increasingly expensive, and adaptation to new products more difficult... Innovative marketing is thus in conflict with production efficiency" (Kilburn, 1976: 17). While such challenges speak to the nested and integrated nature of standards (see Star and Lampland, 2009), they also highlight the additional complications caused by what Lawrence Busch (2011) terms 'standardized differentiation': standards that are designed to differentiate products from each other. Thus, part of the escalating costs of packaging was not merely the interlocking nature of the 
standardized machinery involved, but the drive to differentiate brands from each other. Indeed, a variety of reports reveal that the creation of new brands, or changes to established ones, were extremely costly, based on the attendant changes in packing machinery they required. For example, the minutes of a BAT marketing liaison committee meeting from 21 June 1962 record discussions of efforts to modify a Focke soft cup packer ${ }^{15}$ to enable it to handle a slide-top case and how to deal with the variety of new problems it created - for wrappers, cellophane, etc. A sense of how great these costs are is evident in a Philip Morris document from 2000 regarding the Australian market, which discusses the launch of a new 'Euro pack' box for its Alpine 25s brand that required the investment of "approximately US $\$ 2.4$ million to convert an existing Focke 350 packer to a high speed Focke 350 RC packer” (Gore, 2000: 9).

This material connection between markets, cigarettes and packets comes across strongly in the notes from a technical policy meeting between BAT and Molins held in 1979 that presented Molins' plan for future machinery development (Stewart-Cox, 1979). As outlined in the document, Molins' business philosophy differentiated between three kinds of cigarette markets: Type 1 markets - under-developed countries requiring lower manufacturing outputs; Type 2 markets - advanced developed countries with small brands and requiring mid-range manufacturing outputs; and Type 3 markets - sophisticated countries with large brands requiring very high manufacturing outputs. Cigarette makers and packers were designed to meet the requirements of each of these markets; packets therefore spoke in a material way to the features of their intended markets.

A clear illustration of this relationship can be found in a BAT Information newsletter in the 1950s, which provides a detailed report on the Rose One-Piece Packer: a packing machine designed specifically for the cigarette market in India and Pakistan. According to the report, the packer was created to address the problem of "the provision of a packet superior in appearance and protective qualities to the pre-war 'Unique', ${ }^{16}$ but at the same time cheaper than the hull and slide" (BAT, 1952: 11) - this being what Molins would later define as a 'Type 1' market. The impetus for commissioning the new packer seems to have been the fact that the older packing machines were in need of replacement and the Indian market had been flooded with cigarette manufacturers in the post-war period, which BAT was now competing with for market share. The design of the new one-piece packet (see figure 2) took some time to develop, as did investigations into the most suitable material for it: "cost, protective quality and rigidity being most important considerations" (BAT, 1952: 12). The prototype for the machine was created by Rose Brothers, a pioneering British packaging company, and was then shipped to India for testing. 


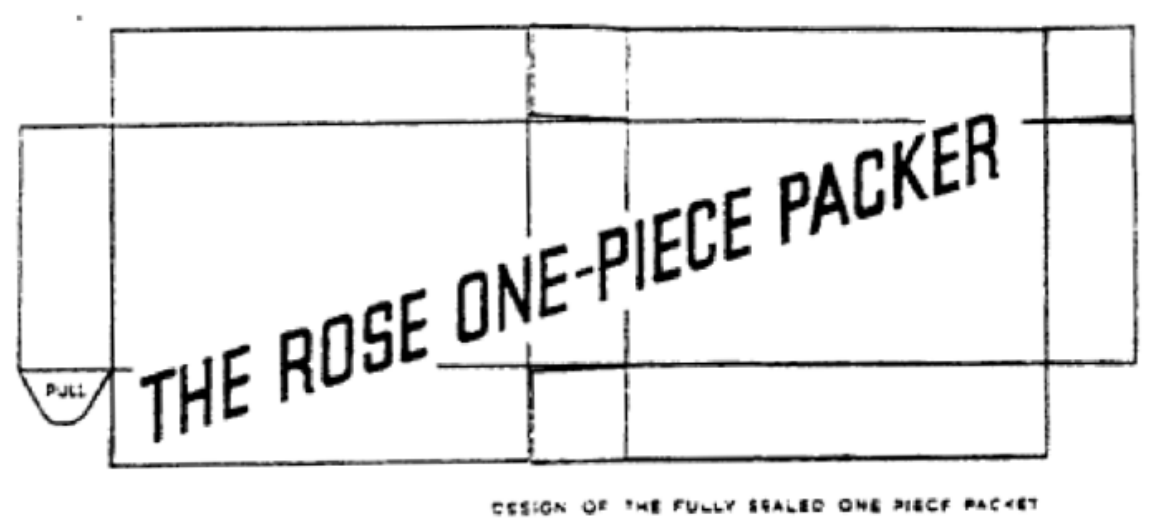

Figure 2. The Rose one-piece packer

Designed primarily for 10-cigarette packs, which are still common in India today, each one-piece packing machine could only make packets of one particular size; no adjustments were possible. It also required a high degree of uniformity in the cigarettes themselves, which could only vary in circumference by $0.5 \mathrm{~mm}$ and in length by $1 \mathrm{~mm}$. Under ideal conditions, the Rose Packer could produce 180 packets per minute, although the author assured readers that "test runs have been made by Rose Bros. during which no difficulty was experienced in running at 200 packets per minute" (BAT, 1952: 13). Importantly, this greater uniformity in the pack size enhanced not only the speed of packet production but their own packability in cartons and containers. These sorts of improvements in the ability of cigarettes to be containerized in large volumes had various consequences, reducing transportation costs and further facilitating their distribution. ${ }^{17}$

But these new packaging technologies clearly affected not just the circulation of cigarettes but Indian smokers themselves. Thus, the report goes on to observe that although the new packets had been very well received, their opening mechanism was causing smokers some difficulties, ${ }^{18}$ and "it has been necessary to educate the trade and public in the correct way of opening the packet" (BAT, 1952: 14). Indeed, as Jeannie's response to her 'new' cigarette packet shows, this seems to be a common consequence of changes in packaging. This raises a number of larger questions about what the materiality of the packet means for smokers themselves and their relationship with cigarettes.

\section{Cigarettes, packets and smokers: matter, matters}

The tobacco industry has long been aware that cigarettes, packets and smokers form a material as well as symbolic assemblage. This is readily apparent in what has become one of the most quoted of all industry documents in the Truth Tobacco Documents archive: a 1972 report by William Dunn Jr of the Philip Morris Research Center titled "Motives and Incentives in Cigarette Smoking." The report is typically used as evidence that the tobacco industry perceived itself as in the business of addicting smokers to nicotine, but particularly interesting for my present purposes is the discussion of the cigarette packet. To quote from the relevant part of the report: 
The cigarette should be conceived not as a product but as a package. The product is nicotine. The cigarette is but one of many package layers. There is the carton, which contains the pack, which contains the cigarette, which contains the smoke. The smoke is the final package. The smoker must strip off all these package layers to get to that which he seeks. But consider for a moment what 200 years of trial and error designing has brought in the way of nicotine packaging: Think of the cigarette pack as a storage container for a day's supply of nicotine:

1) It is unobtrusively portable.

2) Its contents are instantly accessible (Dunn, 1972: 5).

Although clearly wedded to the notion of the cigarette as a nicotine delivery device, Dunn's treatment of the packet as titrative is intriguing insofar as the container does often set a natural limit on how much can be smoked in a day. ${ }^{19}$ Here, in a very concrete sense, the containerization of cigarettes dictates how much people smoke in a way similar to the cigarette itself. ${ }^{20}$ As Busch (2011: 175) observes, "The packaged item comes in various predefined sizes, shapes, weights, colors, and so on. While I may choose among them, I cannot choose between them. In other words, if peas come in 12-oz. and 24-oz. cans, I cannot buy just $14 \mathrm{oz}$. of peas; I must settle for $12 \mathrm{oz}$. or buy a 24 -oz. can”.

This relationship between the packet and consumption patterns becomes particularly apparent when smokers are asked how many cigarettes they consume. Of the more than hundred-odd smokers I have interviewed over the past decade, the vast majority describe their consumption in relation to the packet, rather than how many cigarettes they actually smoke, with the most common category being "a pack a day". Interestingly, the category of the pack-a-day-smoker has now become so naturalized that it's often used in tobacco control accounts as a measure of smoking intensity (for a recent example, see Bricker et al., 2018), with very little reflection on what this actually means. However, while 'typical' packets often contain 20 cigarettes, packs of 10, 25, 30, 40 and 50 are also widely available, depending on the country. Thus, being a pack-a-day smoker doesn't universally mean the same thing; yet, the packet itself typically becomes the critical referent. This suggests that rather than transporting meaning without transformation, packets are entailed in the temporal rhythm of smoking ("a pack a day"), regardless of how many cigarettes they contain. Yet, while the number of cigarettes any given packet contains has been the focus of legislation, requirements invariably focus on the minimum number of cigarettes it can carry. For example, since 2016, British cigarette packets have been required to contain a minimum of 20 cigarettes (Ministry of Health, 2015), which is also the case in many other Western countries. The logic for this legislation is rarely explicitly described, although Article 16 of the Framework Convention on Tobacco Control advises that Party members "shall endeavour to prohibit the sale of cigarettes individually or in small packets which increase the affordability of such products to minors" (WHO, 2003).

The historical variation in the number of cigarettes per packet was unquestionably designed to ensure their affordability for smokers of all income levels; while 10 packs were common in the early twentieth century, so were 'toofers' (two for a penny), 'three for a ha'penny', and so on (Russell, 2017). However, 
tobacco control efforts to legislate pack size seem to be exclusively focused on price: small packets enable tobacco companies to make smokes more affordable, ergo, small packets are bad. In other words, the packet is treated as a neutral enclosure and the focus is exclusively on the objects it contains ${ }^{21}$ - thus, once again, the packet as an object in its own right recedes entirely from view. But if, as I have argued here, the packet's material qualities matter rather more than legislators have assumed, then its materiality is something that clearly ought to be far more explicitly attended to. Matter, in this instance, clearly matters.

As Gay Hawkins (2013) notes in her account of the performativity of food packaging, taking materiality seriously opens up a range of questions about its role in the transformation of food production, consumption and disposal - including the ways it has altered manufacturing processes and the everyday practices of eating. Extending her arguments, she has more recently observed that, "Homogenising plastic, reducing it to a generic bad material with political and environmental effects that are written in advance, does not aid analysis. It blinds us to the diversity of ways in which material and political processes can become interconnected and how these connections emerge" (Hawkins, 2018: 387). Following Hawkins, how might we think differently about the relationship between cigarettes, packets and the everyday practices of smoking if we take the materiality of packaging seriously instead of reducing it to political and social effects that are decided in advance? My sense is that thinking more explicitly about the materiality of cigarette packaging might lead to a rather different set of insights regarding its significance, as two brief examples serve to illustrate.

In 2002, Wakefield and colleagues published the results of a study on the ways cigarette packaging is discussed on tobacco industry websites. Tellingly titled "The cigarette pack as image", the researchers were exclusively interested in the packet as a visual communication device for cigarette brands, despite the implicit evidence they repeatedly present suggesting its material importance. This elision is evident in statements such as:

...unlike many other products where the packaging is discarded after opening, smokers generally retain the cigarette pack until the cigarettes are used and keep the pack close by or on their person. Thus, cigarette packs are constantly being taken out and opened, as well as being left on public display during use. In this way, cigarette packaging can act as an advertisement (Wakefield et al., 2002: i73).

Interpreted differently, instead of highlighting the visual significance of the packet, Wakefield et al.'s statements point to its constant physical presence and integral connection with the act of smoking itself. $^{22}$

This elision is something I have occasionally been guilty of in my own work on cigarette packaging in Canada and smokers' responses to it. In a co-authored paper on this topic (Haines-Saah and Bell, 2016), I discuss the case of 'Sam', a 46-year-old man I met in 2015 out the front of the upmarket downtown hair salon he managed. To quote from the paper: 
Sam did not have his pack of cigarettes on him, given that he had brought only his cigarette and lighter outside. When KB asked if he paid attention to the pack, he was one of the few interviewees who immediately responded: "I do pay attention", indicating that he generally noted which label is on the packet. She then asked if he could recall the label on his cigarette packet and he responded: "it has a picture with a person's lung". If he was smoking a regular packet of Canadian cigarettes, as he claimed, this could not have been the case (Haines-Saah and Bell, 2016: e565).

At the time, I was fixated on the ways that Sam's account challenged the assumption embedded in cigarette packaging legislation that smokers engage with the warning label every time they smoke. In hindsight, what I find most striking about this encounter is the way Sam used the packet - or, rather, its absence - to control his smoking during his breaks. Because Sam was currently trying to quit smoking, without the ready access the packet provided to his smokes he could more easily limit himself to one cigarette.

This is not to suggest that the visual attributes of the cigarette packet don't matter, but to point out that current legislative engagement with it is exclusively in these terms - as Dennis and Alexiou have recently observed: "vision is very obviously the primary sensory means utilized by the government to engage the smoker" (2018: 462-3). Nor I am trying to invoke a straightforwardly deterministic relationship between cigarette consumption and the packet; this is a view that has recently gained a foothold in public health as a result of the growing interest in nudging strategies in influencing 'health behavior' (see Bell, 2017). For example, a recent Cochrane review focuses on the role of portion, package and tableware size for changing the selection and consumption of food, alcohol and tobacco (Hollands et al., 2015), although, to the reviewers' surprise, they were unable to find any studies that explored this question in relation to tobacco use. While this emphasis on the physical environment seems like an advance on the idea of the packet as merely a mobile sign, it - like the transformation of cigarettes into a 'nicotine delivery device' - simply inverts the prevailing approach to objects, where, instead of being too weak, they are now too strong (cf. Latour, 1994, 2005). Instead, my point is that despite its current legislative visibility, cigarette packaging remains an object that everyone "sees and yet doesn't see" (Cochoy and GrandclémentChaffy, 2005: 646) and that a more materially attentive approach to 'seeing' the packet is likely to yield new analytic directions for those interested in reducing the harms of tobacco use. ${ }^{23}$

\section{Conclusion}

Although the power of the cigarette packet is widely recognized in the fields of tobacco control and public health, this agency takes a very particular form. Here, the packet is not an object in its own right but a screen that animates its contents with lively attributes. In such accounts, the branded packet is symbolically powerful but materially inert: its animative powers reside exclusively in the realm of signs rather than things. Contra this view, I have argued that packets are first and foremost containers. And containers have a powerful material role in shaping the circulation of goods and the meanings they hold. 
Containers, after all, contain. To invoke the broader meaning of the term, they restrain, control and behave.

Industry documents suggest that tobacco companies were well aware of these features. Widely recognized to determine the quality of the cigarette itself, packaging was also critical to the mass circulation of cigarettes: shortages in packaging meant shortages in cigarettes. The material affordances of cigarette packets thus served to change the life of smoking, helping to move it to places it had never been before; in other words, they were crucial to assembling markets and smokers (cf. Hawkins, 2011). Critically, the packet and the cigarette were understood as a material unit. Indeed, that the two are inextricably entwined is widely acknowledged in the category of the 'pack-a-day' smoker. No straightforward descriptor, it reveals the material connection between cigarettes and packets and the ways in which the latter mediates the experience of the former. This is readily evident in smokers' accounts, but it requires a new way of thinking about cigarette packets, where their material performativity - i.e., their ability to restrain, control and behave - is forefronted rather than naturalized. This kind of approach is likely to yield benefits for those interested in public health, where the significance of packaging has increasingly come to be appreciated, but in rather restricted and limited ways.

\section{Acknowledgements}

I am indebted to Simone Dennis, Darlene McNaughton and Ciara Kierans for their feedback on the paper prior to submission. Simone, in particular, pushed me to extend my arguments and my thinking on this topic has been greatly enriched by her own work in this area. I have also benefited from the feedback I received in three seminars where I presented incipient versions of these ideas: the CRESIDA seminar series at the University of Roehampton, the London School of Hygiene \& Tropical Medicine Medical Anthropology seminar series, and the Institute of Social Anthropology seminar series at the University of Bern. Finally, thanks are due to the journal editor and three anonymous reviewers, each of whom offered constructive comments and critiques that encouraged me to sharpen my arguments.

\section{Funding}

This research received no specific grant from any funding agency in the public, commercial, or not-forprofit sectors. However, reference is made to an earlier study supported by a Population Health Intervention Research Grant titled "Confronting Cigarette Packaging” jointly funded by the Canadian Institutes of Health Research and the Canadian Cancer Society Research Institute.

\section{Notes}

${ }^{1}$ Ironically, Jeannie's 'new' packet, being a hull and slide design, is a very old style of packaging that substantially predates the flip-top packet. 
${ }^{2}$ Legislation aiming to standardize cigarette packets by removing all industry branding was first implemented in Australia in 2012. At the time of writing, at least seven other countries have either followed suit or are currently in the process of enacting legislation, with many others looking set to follow their lead.

${ }^{3}$ Although Moodie et al. (2012) do consider structural innovations as one of their categories of interest, none of the studies included in their review focus on this.

${ }^{4}$ The FCTC is the first global public health treaty adopted under the auspices of the World Health Organization. At the time of writing, it had been ratified in 181 party countries, which Member countries are expected to enact a set of universal standards for regulating tobacco use.

${ }^{5}$ This is the way Star and Lampland (2009:13) describe the sociology of standardization and infrastructure.

${ }^{6}$ I didn't make a note of exactly how many documents showed up in my initial search in 2018, although the total figure was over 200 (the same search in May 2019 produced 282 documents). However, it's worth noting that the archive includes numerous duplicates and triplicates of documents categorized under different ID numbers, so the actual number of documents I looked at is somewhat lower. I also did supplementary searches in the archives to find specific documents that had been flagged as important through my initial search (e.g., the BAT Information newsletters).

${ }^{7}$ For instance, although they cite William Dunn Jr's (1972) infamous comments about the cigarette pack as a storage container for a day's supply of nicotine (discussed later), they use this quote as a means of highlighting "the crucial importance of packaging as a vehicle for cigarette symbols" (Cross and Proctor, 2014: 82).

${ }^{8}$ And their aggressive response to plain packaging legislation. Various documents in the Truth Tobacco Documents archive indicate that tobacco companies were deeply alarmed by, and playing close attention to, these developments. Indeed, the tobacco industry's response to plain packaging has merely served to intensify tobacco control researchers' sense of the importance of the cigarette packet as a sign vehicle.

${ }^{9}$ According to Alford (1973), it was during this period that packing machines were introduced in the UK; this was also the period in which cigarette vending machines came into widespread use (see Proctor, 2011).

${ }^{10} \mathrm{~A}$ 'hull and slide' packet, also known as a 'slide and shell' packet, contains two discrete components: an outer shell and an inner box, which is slid out of the cover, much in the fashion of a contemporary matchbox.

${ }^{11}$ This is the term Henry Ford famously used to describe cigarettes in his 1914 treatise The Case Against the Little White Slaver.

${ }^{12}$ My heavy reliance on BAT documents throughout this paper reflects their broader prominence in the results of my keyword search on 'packet design'.

${ }^{13}$ This was a series of confidential newsletters produced between 1946-1953, although these are only approximate estimates based on what I have been able to uncover in the Truth Tobacco Documents archive. In total, there are 15 issues in the archive. However, the last issue provides every indication that the periodical planned to continue, so it's possible that it did so under another name or that the archives do not contain the full collection of newsletters.

${ }^{14}$ British American Tobacco was the product of a joint venture between the Imperial Tobacco Company and the American Tobacco Company that aimed to end their intense trade war. Under the agreement that led to the company's formation, the two companies could not trade in each other's domestic markets (BAT, 2007). 
${ }^{15}$ Details on the Focke soft cup packer are available on the company's website, which provides further illustration of the material connection between packets and cigarettes and the degree of integration between them (see Focke, 2019).

${ }^{16}$ The Unique 10s packet was made from a very cheap indigenous cardboard that was sealed on three slides and closed via a tongue-shaped flap that was inserted into a slot in the back of the packet. As its name suggests, it was sized to fit 10 cigarettes.

${ }^{17}$ As Levinson (2006) shows, transport company fortunes were made on the back of tobacco and tobacco manufacturers such as R.J. Reynolds likewise invested heavily in the shipping container business. However, the containerization of cigarette packets raised a new set of technical problems in terms of ensuring their physical integrity when stored together in large volumes. This is implicitly referenced in the focus on the Rose packet's 'rigidity' but it makes an explicit appearance in later industry documents on packet strength and the issue of pack compression. For example, a British American Tobacco report (1980) highlights a number of tests on front panel rigidity, skew resistance and compression resistance.

${ }^{18}$ Unlike the old Unique 10s, where the packet was opened by tearing off the flap completely to expose all 10 cigarettes, the Rose packet was opened by tearing the top flap only to the extent that the two end cigarettes were exposed.

${ }^{19}$ Smokers can obviously store packets in different locations, but I think the broader point still holds that at any given point in time, a person is not likely to have access to more than one packet of cigarettes.

${ }^{20}$ Cigarettes are, of course, designed to be smoked in one sitting - a feature that has been widely discussed in popular culture (e.g., the 1997 film Romy and Michele's High School Reunion). This is exactly how the majority of smokers use them - although in downtown Vancouver it is common to see homeless people scavenging used cigarette butts to smoke (see Haines-Saah and Bell, 2016).

${ }^{21}$ This is an explicit aspect of tobacco taxation strategies - a Philip Morris document focusing on the Australian context discusses the introduction of a stick-specific tax in 1999 and its implications for consumption patterns, highlighting that it had given premium brands an edge and discussing strategies for capitalizing on this (Gore, 2000).

${ }^{22}$ The centrality of the packet to smoking itself is evident as soon as we look beyond academic accounts of smoking. See, for example, the "How to smoke a cigarette" section on the WikiHow site (WikiHow, 2019), which begins its demonstration of smoking with the tamping and opening of the packet, or the 1930s anti-smoking treatise Death In Cellophane (Van Knoppen, 1937), whose title points to the intrinsic connection between smoking and the pack.

${ }^{23}$ For example, it would be interesting to consider the history and effects of the containerization of loose-leaf tobacco, which is rather more resistant to standardization in terms of how smokers use it. 


\section{References}

Alford BWE (1973) W.D. and H.O. Wills and the Development of the U.K. Tobacco Industry: 1786-1965. London: Methuen.

Arvidsson A (2006) Brands: Meaning and Value in Media Culture. London: Routledge.

Bell K (2017) Nudging and other theories of 'health behaviour'. In: Health and Other Unassailable Values: Reconfigurations of Health, Evidence and Ethics. London: Routledge, pp. 32-51.

Bell K, Dennis S, Robinson J and Moore R (2015) Does the hand that controls the cigarette packet rule the smoker? Findings from ethnographic interviews with smokers in Canada, Australia, the United Kingdom and the USA. Social Science and Medicine 142: 136-144.

Brandt AM (2007) The Cigarette Century: The Rise, Fall, and Deadly Persistence of the Product that Defined America. New York: Basic Books.

Braun B and Whatmore SJ (2010) The stuff of politics: An introduction. In: Braun B and Whatmore SJ (eds) Political Matter: Technoscience, Democracy, and Public Life. Minneapolis: University of Minnesota Press, ix-xl.

Bricker J, Sridharan V, Zhu Y, et al. (2018) Trajectories of 12-month usage patterns for two smoking cessation websites: Exploring how users engage over time. Journal of Medical Internet Research 20(4): e10143.

British American Tobacco (1948) Information: A Periodical Summary of Ideas from all Quarters. Issue 7 (November). XTHP0192, Tobacco Truth Industry Documents, University of California San Francisco Library.

British American Tobacco (1952) Information: A Periodical Summary of Ideas from all Quarters. Issue 14 (November). XHXG0207, Tobacco Truth Industry Documents, University of California San Francisco Library.

British American Tobacco (1953) Information: A Periodical Summary of Ideas from all Quarters. Issue 15 (May). JHXG0207, Tobacco Truth Industry Documents, University of California San Francisco Library.

British American Tobacco (1962a) Marketing Liaison Committee Meeting Minutes. FQGL0032, Tobacco Truth Industry Documents, University of California San Francisco Library. 
British American Tobacco (1962b) Meeting of Committee of Directors - 1962. TPGL0032, Tobacco Truth Industry Documents, University of California San Francisco Library.

British American Tobacco (1964) British-American Tobacco Company Limited: Board of Directors. MGW0192, Tobacco Truth Industry Documents, University of California San Francisco Library.

British American Tobacco (1980) Technical Memorandum. LNNC0198, Tobacco Truth Industry Documents, University of California San Francisco Library.

British American Tobacco (2007) Early years: 1902-1932. British American Tobacco (archived). Available at:

https://web.archive.org/web/20090209050411/http://www.bat.com/group/sites/UK_3MNFEN.nsf/vwP agesWebLive/DO5DTGBV ?opendocument\&SKN=3 (accessed 12 July 2018).

Brown EH (2008) Marlboro men: Outsider masculinities and commercial modeling in postwar America. In: Blaszczyk RL (ed) Producing Fashion: Commerce, Culture, and Consumers. Philadelphia: University of Pennsylvania Press, pp. 187-206.

Busch L (2011) Standards: Recipes for Reality. Cambridge: The MIT Press.

Callaham WT (1988) New Product Technology. KJKM0000, Tobacco Truth Industry Documents, University of California San Francisco Library.

Chantler C (2014) Standardised Packaging of Tobacco: Report of the Independent Review Undertaken by Sir Cyril Chantler. Department of Health, London. http://www.kcl.ac.uk/health/10035-TSO-2901853Chantler-Review-ACCESSIBLE.PDF (accessed 15 December 2018).

Chapman S and Freeman B (2014) Removing the Emperor's Clothes: Australia and Tobacco Plain Packaging. Sydney: Sydney University Press.

Cochoy F (2002) Une Sociologie du Packaging ou l'âne de Buridan Face au Marché: Les Emballages et le Choix du Consommateur [A Sociology of Packaging, or the Buridian's Ass Facing the Market: Packaging and Consumer Choice]. Presses Universitaires de France.

Cochoy F and Grandclément-Chaffy C (2005) Publicizing Goldilocks' choice at the supermarket: The political work of shopping packs, carts and talk. In: Latour B and Weibel P (eds) Making Things Public: Atmospheres of Democracy. Cambridge: MIT Press, 646-657. 
Cronin AM (2004) Advertising Myths: The Strange Half-lives of Images and Commodities. London: Routledge.

Cross, GS and Proctor RN (2014) Packaged Pleasures: How Technology and Marketing Revolutionized Desire. Chicago: University of Chicago Press.

Dennis S and Alexiou H (2018) (Re)making smoking: Of packets and practice. Journal of Material Culture 23(4): 459-471.

Dunn EC (2009) Standards without infrastructure. In: Lampland M and Star SL (eds) Standards and Their Stories: How Quantifying, Classifying, and Formalizing Practices Shape Everyday Life. Ithaca: Cornell University Press, pp. 118-121.

Dunn WL (1972) Motives and incentives in cigarette Smoking. Philip Morris Research Center. JSPF0085, Tobacco Truth Industry Documents, University of California San Francisco Library.

Dwyer RW (1987) Cigarette Design Project. Project Number 2106. QYKF0143, Tobacco Truth Industry Documents, University of California San Francisco Library.

Focke (2019) Cigarette packaging \& OTP. https://www.focke.com/cigarette-packaging-otp/soft-cuppacker/ (accessed 4 June 2019).

Ford H (1914) The Case Against the Little White Slaver: Volumes 1, 2, 3 and 4. Detroit: Ford.

Gore J (2000) CPC Submission - Alpine Cigarettes (Australia). LHBV0152, Tobacco Truth Industry Documents, University of California San Francisco Library.

Haines-Saah R and Bell K (2016) Challenging key assumptions embedded in Health Canada's cigarette packaging legislation: Findings from in-situ interviews with smokers in Vancouver. Canadian Journal of Public Health 107(6): eS62-eS67.

Hammond D (2011) Health warning messages on tobacco products: A review. Tobacco Control 20(5): 327-337.

Harrald C and Watkins F (2010) The Cigarette Book: The History and Culture of Smoking. New York: Skyhorse Publishing.

Hawkins G (2013) The performativity of food packaging: Market devices, waste crisis and recycling. The Sociological Review 69(S2): 66-83. 
Hawkins G (2018) The skin of commerce: Governing through plastic food packaging. Journal of Cultural Economy 11(5): 386-403.

Hollands GJ, Shemilt I, Marteau TM, et al. (2015) Portion, package or tableware size for changing selection and consumption of food, alcohol and tobacco. Cochrane Database of Systematic Reviews 9, art. no.: CD011045.

Ingold T (2007) Materials against materiality. Archaeological Dialogues 14(1): 1-16.

Kilburn KD (1976) Technological Forecasting: A Brief Survey of Trends, Opportunities, and Possible Consequences of Change in the Technology of Making and Packing Cigarettes. Report No. RD. 1353 Restricted. JMLK0196, Tobacco Truth Industry Documents, University of California San Francisco Library.

Kopytoff I (1986) The cultural biography of things: Commoditization as process. In: Appadurai A (ed) The Social Life of Things: Commodities in Cultural Perspective. Cambridge: Cambridge University Press, 64-92.

Latour B (1994) On Technical mediation - Philosophy, sociology, genealogy. Common Knowledge 3(2): 29-64.

Latour B (2005) Reassembling the Social: An Introduction to Actor-Network-Theory. Oxford: Oxford University Press.

Levinson M (2006) The Box: How the Shipping Container Made the World Smaller and the World Economy Bigger. Princeton: Princeton University Press.

Lury C (2004) Brands: The Logos of the Global Economy. London: Routledge.

Miller D (2010) Stuff. Cambridge: Polity Press.

Ministry of Health (2015) The Standardised Packaging of Tobacco Products Regulations 2015. Available at: https://www.legislation.gov.uk/ukdsi/2015/9780111129876/contents (accessed 15 June 2018).

Monárrez-Espino J, Liu B, Greiner F, Bremberg S and Galanti R (2014) Systematic review of the effect of pictorial warnings on cigarette packages in smoking behavior. American Journal of Public Health 104: e11-e30. 
Moodie C, Stead M, Bauld L, McNeill A, Angus K, Hinds K, Kwan I, Thomas J, Hastings G and O'MaraEves A. (2012) Plain tobacco packaging: a systematic review. Public Health Research Consortium. Available at: http://phrc.lshtm.ac.uk/papers/PHRC_006_Final_Report.pdf (accessed 22 May 2019).

Mpac Group (2019) Our long history. http://mpac-group.com/about-us/history/ (accessed 5 January 2019).

Noar SM, Francis DB, Bridges C, Sontag HM, Ribisl KM and Brewer NT (2016a) The impact of strengthening cigarette pack warnings: Systematic review of longitudinal observational studies. Social Science and Medicine 164: 118-129.

Noar SM, Hall MG, Francis DB, Ribisl KM, Pepper JK and Brewer NT (2016b) Pictorial cigarette pack warnings: a meta-analysis of experimental studies. Tobacco Control 25(3): 341-354.

Peirce CS (1998) The Essential Peirce. Selected Philosophical Writings, Vol. 2 (1893-1913), The Peirce Edition Project (eds). Bloomington, IN: Indiana University Press.

Philip Morris (1988) Monthly Progress Reports - Period Covered 88/10/01-88/10/31. QNDY0002, Tobacco Truth Industry Documents, University of California San Francisco Library.

Pottage A (2013) No (more) logo: Plain packaging and communicative agency. University of California Davis Law Review 47: 101e131.

Proctor R (2011) Golden Holocaust: Origins of the Cigarette Catastrophe and the Case for Abolition. Berkeley: University of California Press.

Russell BK (2012) Collecting early cigarette packets. YouTube.

https://www.youtube.com/watch?v=cQ2PQmIgcRM (accessed 1 September 2018).

Russell BK (2017) Early cigarette packets II: How many cigarettes are there in a packet? YouTube. https://www.youtube.com/watch?v=qHvdqy1TG5g (accessed 1 September 2018).

Star SL and Lampland M (2009) Reckoning with standards. In: Lampland M and Star SL (eds) Standards and Their Stories: How Quantifying, Classifying, and Formalizing Practices Shape Everyday Life. Ithaca: Cornell University Press, pp. 3-24.

Stead M, Moodie C, Angus K, Bauld L, McNeill, Thomas J, Hastings G, Hinds K, O’Mara-Eves A, Kwan I, Purves RI and Bryce SL (2013) Is consumer response to plain/standardised tobacco packaging 
consistent with Framework Convention on Tobacco Control guidelines? A systematic review of quantitative studies. PLoS ONE 8(10): e75919.

Stevenson T and Proctor RN (2008) The SECRET and SOUL of Marlboro: Phillip Morris and the origins, spread and denial of nicotine freebasing. American Journal of Public Health 98(7): 1184-1194.

Stewart-Cox AR (1979) Notes on Technical Policy Meeting Between BAT and Molins. XMVD0205, Tobacco Truth Industry Documents, University of California San Francisco Library.

Van Knoppen CL (1937) Death In Cellophane. Greensborough: Charles L. Van Knoppen.

Wakefield M, Morley C, Horan JK and Cummings KM (2002) The cigarette pack as image: new evidence from tobacco industry documents. Tobacco Control 11(Suppl I): i73-i80.

Whorf B (1941) The relation of habitual thought and behaviour to language. In Spier L (ed) Language, Culture, and Personality: Essays in Memory of Edward Sapir. Menasha: Sapir Memorial Publication Fund, pp. 75-93.

Wikihow (2019) How to smoke a cigarette. https://www.wikihow.com/Smoke-a-Cigarette

World Health Organization (2003) WHO Framework Convention on Tobacco Control. Geneva: World Health Organization. 